\section{Consumer Preferences for Color, Price, and Vitamin C Content of Bell Peppers}

\author{
Christopher A. Frank ${ }^{\mathbf{1}}$ and Robert G. Nelson ${ }^{2}$ \\ Department of Agricultural Economics and Rural Sociology, 202 Comer Hall, \\ Auburn University, AL 36849-5406
}

\author{
Eric H. Simonne ${ }^{3}$ and Bridget K. Behe ${ }^{4}$ \\ Department of Horticulture, 101 Funchess Hall, Auburn University, \\ AL 36849-5408
}

\author{
Amarat H. Simonne \\ Department of Nutrition and Food Science, Spidle Hall, Auburn University, \\ AL 36849-5605
}

\begin{abstract}
Additional index words. Capsicum annuum, conjoint analysis, market segmentation, multinomial logit
\end{abstract}

\begin{abstract}
Most bell peppers (Capsicum annuum L.) produced and consumed are green. However, yellow, red, orange, white, black, and purple bell peppers are also available. While bell pepper consumption in the United States has been increasing in the past 10 years, limited information is available on how their color, retail price, and vitamin $\mathrm{C}$ content influence consumer preferences. A conjoint analysis of 435 consumer responses showed that, for the total sample, color was about three times more important than retail price in shaping consumers' purchase decisions, while vitamin $C$ content was nearly irrelevant. Six distinct consumer segments were identified through cluster analysis. Four segments favored green peppers, while one segment favored yellow and one favored brown. Demographic variables generally were not good predictors of segment membership, but several behavioral variables, such as past bell pepper purchases, were significantly related to segment membership. While green is generally the preferred color, market segments exist for orange, red, yellow, and even brown peppers. Applications to marketing strategies suggested that price sensitivity could explain why green peppers were priced individually, but those of other colors were priced by weight, and that promotion of increased vitamin $C$ content would be most effective if associated specifically with yellow and orange peppers.
\end{abstract}

Bell peppers are becoming an increasingly popular decorative and nutritive food item in the United States. Per capita consumption of bell peppers in the United States nearly tripled in the last three decades, rising from $1.1 \mathrm{~kg}$ per capita per year in 1973 to 3.2 in 1996 , representing a total value of domestic bell pepper production of $\$ 461$ million (U.S. Dept. of Agriculture, 1997a). However, there is little published information about consumer prefer-

Received for publication 26 Apr. 1999. Accepted for publication 16 Sept. 2000. The cost of publishing this paper was defrayed in part by the payment of page charges. Under postal regulations, this paper therefore must be hereby marked advertisement solely to indicate this fact.

${ }^{1}$ Former Graduate Research Assistant.

${ }^{2}$ Professor.

${ }^{3}$ Assistant Professor; to whom reprint requests should be addressed. Current address: Horticultural Sciences Dept., 1241 Fifield Hall, P.O. Box 110690 , Univ. of Florida, Gainesville, FL 32611-0690. Email address: esimonne@mail.ifas.ufl.edu ${ }^{4}$ Associate Professor. Current address: Dept. of Horticulture, 216 Plant and Soil Sciences, Michigan State Univ., East Lansing, MI 48824-1325.

${ }^{5}$ Assistant Professor. Current address: Dept. of Family, Youth \& Community Sciences, P.O. Box 110310 , Univ. of Florida, Gainesville, FL 32611-0310. ences for various attributes of bell peppers, such as demographic influences on color choice, the importance of retail price in the purchase decision, and the desirability of certain nutritive qualities. In this study, we use conjoint analysis to examine consumer preferences for some of these attributes, and discuss some marketing implications of our results.

Conjoint analysis is useful in determining how various product attributes and their levels influence a consumer's purchase decision. For example, it can reveal whether one level of an attribute, such as low vitamin content, has a positive or negative influence on a consumer's purchase decision, or whether a consumer's preferences are sensitive to price. Larger positive values for one level of an attribute (e.g., yellow color, high vitamin content) indicate that it is preferred more than those with smaller values (e.g., brown color, low vitamin content). Attributes with wider ranges of values across levels have greater "relative importance" in the purchase decision than attributes with narrower ranges of levels.

Conjoint analysis has been used in a number of horticultural applications. Robertson and Chatfield (1982) evaluated consumer preferences for bunch composition, color, and price in loose-bunch merchandising of fresh flowers. Shafer and Kelly (1986) assessed the influence of cultivar, price, and longevity on consumer preferences for potted chrysanthemums. Gineo (1990) studied rhododendron sales from wholesalers to retail garden centers and landscapers to determine the importance of quality, plant height, container size, price, region of origin, range of products offered, flower color, delivery time, and payment terms. Manalo (1990) evaluated consumer preferences for size, color, price, crispness, and flavor in apples. Townsley-Brascamp and Marr (1995) analyzed consumer preferences for characteristics of outdoor ornamentals, such as plant health, bushiness, height, price, suitability for growing conditions, shape, flower color, and leaf color. Behe et al. (1999) evaluated consumer preferences for geranium flower color, leaf variegation, and price.

A number of attributes may affect consumer preferences for bell peppers, including aspect (color, size, shape), nutritive value (vitamin $\mathrm{C}$, provitamin A, minerals, fiber), intended use (frozen, pre-sliced, or diced for cooking; whole fruits for fresh consumption), and retail price. Since only a few of these attributes could be examined simultaneously, some choices had to be made about which ones to include in this study.

Color was an obvious first choice of attribute. While green is by far the most preferred color in bell peppers, red and yellow are also popular choices, especially as garnishes. Market shares are roughly $80 \%, 10 \%$, and $8 \%$ for the three colors, respectively. The remaining $2 \%$ of the market is divided among a variety of other colors, including orange, purple, black, brown, and ivory (Simonne et al., 1997b).

Price was another obvious attribute that influences consumers' preferences for bell peppers. Green bell peppers usually sell for a lower price than peppers of other colors. For example, in Sept. 1997 the Atlanta terminal market wholesale price for a $13-\mathrm{kg}$ box of large green peppers ranged from $\$ 8.00$ to $\$ 10.25$, while red, yellow, or orange peppers ranged from $\$ 16.00$ to $\$ 23.50$ (U.S. Dept. of Agriculture, 1997b). In 1998, retail prices for green bell peppers in stores in the Auburn, Ala., area typically ranged from $\$ 1.52$ to $\$ 2.18$ per $\mathrm{kg}$, while prices for peppers of other colors ranged from $\$ 6.57$ to $\$ 10.98$ per $\mathrm{kg}$. These prices appear to reflect differences in consumer preferences rather than differences in cost of production.

Although bell peppers are primarily chosen as a colorful enhancement in food preparation, the fact that bell peppers are an excellent source of vitamin $\mathrm{C}$ and a good source of vitamin A is less well known. In fact, in a survey of vitamin $\mathrm{C}$ content of fruits and vegetables, bell peppers ranked fourth highest out of 42 alternatives (Salunkhe, 1976). Interestingly, green bell peppers are lower in vitamin $C$ content than bell peppers of other colors. Concentrations of vitamin $\mathrm{C}$ range from $980 \mathrm{mg} \cdot \mathrm{kg}^{-1}$ in green peppers to 1080 in orange peppers (Simonne et al., 1997a). These factors recommended vitamin $\mathrm{C}$ content as a third attribute that might prove useful in differentiation of bell peppers by consumers. 
While changes in color during fruit development and nutritional content for different colors of bell peppers are well documented and understood, limited information is available on how consumers evaluate these factors in making their purchasing decisions. An understanding of consumers' preferences for bell peppers would be of interest to breeders, producers, wholesalers, and retailers. Therefore, the objectives of this study were to: 1) quantify consumer preferences for color, retail price, and vitamin $\mathrm{C}$ content in bell peppers; 2) identify different segments of consumers with different preferences; and 3) determine how demographic and behavioral variables affect the probability of a consumer being in a particular segment.

\section{Materials and Methods}

Conjoint analysis was used to identify the structure of consumer preferences by modeling their decision-making processes from their evaluations of the main attributes associated with bell peppers (Green and Wind, 1973). First, a set of attributes called a "product profile" was created by combining attributes at levels that reflected the market ranges consumers routinely use to assess bell peppers. In this study, the attributes selected were color, retail price, and vitamin C content. Samples of Fancy grade green, brown, red, yellow, and orange bell peppers from the 1996 Auburn Univ. cultivar trials were used (Simonne et al., 1996). Selected prices were $\$ 1.52, \$ 3.73, \$ 5.93$, and $\$ 8.13 / \mathrm{kg}$. Selected vitamin C contents (per serving) were $75 \%, 100 \%$, and $125 \%$ of the U.S. Recommended Daily Allowance (RDA). Although these levels may not accurately represent the actual ranges of vitamin $C$ found in bell peppers, they were subjectively chosen to elicit preferences for "lower-thanaverage," "average," and "higher-than-average" concentrations of vitamin C.

The survey was conducted on a Saturday and Sunday in Aug. 1996 in the Auburn, Ala., area. Bell peppers were displayed in the produce section of two large retail grocery stores of the same chain. Consumers voluntarily participating in the survey were provided with a clipboard, a pen, instructions, and a questionnaire. Several plates, each containing three whole, fresh bell peppers and a card with a retail price and a vitamin $\mathrm{C}$ level, were randomly placed on a table. Consumers were asked to evaluate each plate on a 1-to-5 scale displayed on their questionnaire as follows:

\begin{tabular}{|c|c|c|}
\hline $\begin{array}{c}\text { Definitely would } \\
\text { NOT buy }\end{array}$ & $\begin{array}{c}\text { May or } \\
\text { may not buy }\end{array} \quad \begin{array}{c}\text { Definitely } \\
\text { would buy }\end{array}$ \\
$1 \ldots \ldots$ & $\ldots \ldots .3 \ldots \ldots 4 \ldots \ldots 5$ \\
\hline
\end{tabular}

They were also asked to assume that the peppers were to be used raw. The total number of possible product combinations was 60 (five colors $\times$ four prices $\times$ three vitamin $C$ levels). To make the number of product profiles and the length of the questionnaire more manageable for respondents, a factorial design generated by Bretton-Clark's Conjoint Designer software (Bretton-Clark, 1990) was used to reduce the number of profiles to 32 , which were then randomly subdivided into two sets of 16 each.

Consumers were also asked to provide demographic and behavioral information. Demographic information included consumer's age, gender, years of formal education, household size, and income. In reference to purchase behavior in the previous 4 weeks, behavioral information included purchase of any bell peppers, specific colors purchased, estimated consumption (in pounds), and method of preparation (cooked or raw).

Consumers' preference ratings were analyzed using Bretton-Clark's Conjoint Analyzer software (Bretton-Clark, 1992). Rather than aggregating all participants and obtaining average preferences, this program generated preference estimates for each participant. This individual-level approach reduces bias in results when researchers have reason to believe that different segments of respondents have markedly different preferences (Bretton-Clark, 1992). Most previous horticultural applications of conjoint analysis have assumed homogeneous preferences and have used aggregatelevel analysis (Gineo, 1990; Manalo, 1990; Robertson and Chatfield, 1982; Shafer and Kelly, 1986; Townsley-Brascamp and Marr, 1995).

Before estimating the conjoint model, functional forms were selected for each attribute. A dummy variable, or "part-worth," functional form was selected for both color and vitamin C content because of its flexibility in approximating the preference function. For color, the choice was obvious because color is a qualitative variable with no prior expectations regarding the shape of the preference function. In the case of vitamin $\mathrm{C}$ content, we were uncertain whether consumers would prefer more vitamin C (125\% RDA) because of its widely reported health benefits, lower dosages (75\% RDA), or exactly $100 \%$ RDA. Price can be represented with either a linear (or "vector") model or a quadratic (or "ideal point") model. A pretest using a full- vs. restrictedmodel F-test showed no significant difference between the two models, so the more parsimonious linear model was chosen to conserve degrees of freedom.

The following functional form of the model was estimated with ordinary least squares regression:

$$
\begin{aligned}
\mathrm{R}= & \alpha+\beta_{1} \mathrm{C}_{1}+\beta_{2} \mathrm{C}_{2}+\beta_{3} \mathrm{C}_{3}+\beta_{4} \mathrm{C}_{4}+ \\
& \gamma \mathrm{P}+\delta_{1} \mathrm{~V}_{1}+\delta_{2} \mathrm{~V}_{2}+\mathrm{e}
\end{aligned}
$$

where $\mathrm{R}$ was the rating assigned by a respondent to a particular product combination (i.e., a plate of three raw peppers of the same color, along with the price and vitamin $\mathrm{C}$ content); $\mathrm{C}_{\mathrm{i}}$ represented four of the five colors, designated by effects-coded indicator variables (Cohen and Cohen, 1983; Hardy, 1993); P represented price, modeled as a continuous variable; $\mathrm{V}_{\mathrm{i}}$ represented two of the three levels of vitamin C content, also designated by effects-coded indicator variables; and e represented a normally distributed random error term. To facilitate interpretation of part-worths, the coefficient for the omitted fifth color was calculated as the negative sum of the included color coefficients; similarly for vitamin C content. Since each of the 435 respondents rated 16 plates, there were 16 observations available to estimate each individual respondent's model, with a total of 435 such models estimated.

The estimated part-worth and vector coefficients were next analyzed with cluster analysis, which aggregated the preferences of individuals into consumer segments based on similarity of preferences (Green and Helsen, 1988). The cluster analysis was done using the PROC CLUSTER procedure in SAS (SAS Institute, 1996), specifying Ward's minimum variance method. The determination of the number of clusters was based on local peaks in the cubic clustering criterion and pseudo $\mathrm{F}$ statistic at six clusters, as well as a sharp drop in the pseudo $t^{2}$ statistic, also at six clusters (SAS Institute, 1996).

After cluster analysis of the part-worths, consumers' demographic and behavioral variables were analyzed to establish which variables were significant in determining cluster membership, using two different approaches. The first approach was simply to test the means of each preference segment against the overall mean. The second approach was to relate consumers' demographic and behavioral variables to their segment membership by estimating a multinomial logit model using LIMDEP (Greene, 1995). This method provides a measure of the relative impact of these variables on the probability of membership in a particular segment, as well as the change in that probability given a specific change in the independent variable of interest (Huang and $\mathrm{Fu}, 1995)$

The multinomial logit model determines the probability of a respondent belonging to a particular cluster or consumer segment, and is specified as:

$$
\begin{gathered}
\operatorname{Prob}[\text { segment }=j]=\frac{e^{B_{j} X_{i}}}{1+\sum_{j=1}^{m-1} e^{B_{j} X_{i}}} \\
j=1, \ldots, \mathrm{m}-1 \quad i=1, \ldots, \mathrm{n}
\end{gathered}
$$

where Prob [segment $=j]$ denotes the probability that a respondent belongs to the $\mathrm{j}^{\text {th }}$ consumer segment, $X_{\mathrm{i}}$ represents a set of $n$ demographic and behavioral characteristics of the respondents, and $\mathrm{B}_{\mathrm{j}}$ is a vector of parameters to be estimated for the $m-1$ segments. Parameters are estimated for only $m$ - 1 segments because one of the segments must be normalized to zero in order to fully identify the model (Greene, 1995). In interpreting the coefficients, this omitted segment (in our case, Segment I) becomes the reference for comparison, such that the estimates from this model predict the probability of an individual being in one of the $m-1$ segments and not in the reference group. For example, a positive sign on the coefficient for gender for Segment IV would indicate that women are more likely to be members of Segment IV than of Segment I. Because such interpretations are conditional on the omitted segment, they are not useful in relating a change in the probability of segment membership to a change in a given socioeconomic 
variable, and for this reason a table of these coefficients is not included in this text. However, an analysis of marginal effects does permit estimation of such changes in probability, allowing the interpretation that a $1 \%$ increase in the proportion of females in the sample would change the probability of membership in Segment IV by the value of the coefficient in a table of marginal probabilities.

The derivation of marginal effects is as follows:

$$
\begin{gathered}
\eta_{j i}=\frac{\partial \operatorname{Prob}[\text { segment }=j]}{\partial X_{i}}=P_{j}\left[B_{j i}-\sum_{j=1}^{m-1} P_{j} B_{j i}\right] \\
j=1, \ldots, \mathrm{m}-1 \quad i=1, \ldots, \mathrm{n}
\end{gathered}
$$

where $\eta_{j i}$ represents the change in the probability of a respondent being associated with segment $\mathrm{j}$ with respect to a one-unit change in the $i^{\text {th }}$ socioeconomic characteristic, $X_{i} . P_{j}$ is the observed probability of group membership, Prob[segment=j]. $B_{j i}$ is the estimated regression coefficient associated with $X_{i}$ for segment $\mathrm{j}$. The derivative is evaluated at the overall sample mean of $X_{i}$, where the effects of $B_{j i}$ on changes in probability are greatest. Because an increase in the probability of being in one segment must be offset by a decrease in the probability of being in another segment, the marginal probabilities for a given independent variable sum to zero.

The demographic variables used in the multinomial logit model were age, income, gender, education, and household size. Gender was a binary variable with $1=$ "female." The behavioral variables were: purchase of any bell peppers within the last month; specific colors purchased within the last month; total weight purchased within the last month; and method of preparation (cooked or raw). Since no respondent had purchased brown peppers, this variable was omitted.

The level of significance used to interpret all statistical tests was $10 \%$ or less. Extrapola- tion of the results to a wider population is conditional on the representativeness of the sample of participants, so the following results and discussion should be evaluated with this limitation in mind.

\section{Results and Discussion}

Overall panel. A total of 435 consumers completed the questionnaire. The following analysis of the entire sample (the "overall panel") is similar to the aggregate-level approach used in most previous horticultural applications of conjoint analysis.

Color was overwhelmingly the most important attribute, with a relative importance of 75\% (Table 1, last column). The part-worths for the levels of color indicated a strong preference for green (with a part-worth of 0.91), while brown had a large negative effect on preference $(-0.85)$. The overall panel perceived red, yellow, and orange as intermediate between these two extremes, with similar partworths. Retail price, with a relative importance of $23 \%$, was only about a third as important in the buying decision, over this range of prices. Vitamin $\mathrm{C}$ content had an even lower importance $(2.5 \%)$.

The marked preference for green, together with the subordinate influence of price relative to color, suggested that in this market the shares of alternative colors could not be increased simply by lowering their retail prices. Also, the low part-worth for brown in the overall sample suggested that there would be no market for this color. Conversely, consumers' preference for orange, which was similar to that of red and yellow, indicated that orange was underrepresented in the current market share. This may have been due to the limited availability of orange cultivars with desirable horticultural attributes, such as high-yield potential, heat tolerance, and disease resistance (Simonne et al., 1997b).
The small relative importance of vitamin $\mathrm{C}$ content in overall consumer preferences $(2.5 \%)$ initially seemed to suggest that this would be an unpromising attribute on which to differentiate bell peppers and promote their consumption. However, analysis of the six panel segments indicated otherwise.

Panel segments. Cluster analysis revealed the potential for consumer segmentation strategies. Most of the part-worth coefficients within each of the six segments were significantly different from those of the overall panel (see second footnote in Table 1). Sixteen of the 18 relative-importance summary statistics, and 39 of the 54 part-worths for the six segments differed significantly from those of the overall sample, confirming that the clustering method was efficient in sorting consumers into distinct segments.

Color was still the dominant contributor to consumer preference in five of the six segments. All but four of the segments' partworths for color were significantly different from those of the overall sample. Yet, strong preferences for green and strong dislikes for brown were still found in four of the six segments (Segments II, III, IV, and V). Moreover, in comparison with the overall sample, Segments III and IV showed a much stronger preference for green peppers.

Segment I represented $10 \%$ of the sample, and contained consumers with strong preferences for yellow and, to a lesser extent, orange. Brown was the preferred color for Segment VI ( $8 \%$ of the sample), suggesting that a small market for brown bell peppers may exist and that retailers in this location should consider stocking a limited quantity of this color. For nearly half of the sample (comprising Segments I, II, and III), orange had the second highest positive part-worth among colors. Red was neither strongly liked nor disliked by any segment. Red preference was highest in Segments $\mathrm{V}$ and VI, where red had the second

\begin{tabular}{|c|c|c|c|c|c|c|c|}
\hline Attributes and levels & $\begin{array}{c}\text { Segment I } \\
(10.3 \%) \\
\text { Part-worth }\end{array}$ & $\begin{array}{c}\text { Segment II } \\
(24.8 \%) \\
\text { Part-worth }\end{array}$ & $\begin{array}{c}\text { Segment III } \\
(12.0 \%) \\
\text { Part-worth }\end{array}$ & $\begin{array}{c}\text { Segment IV } \\
(27.6 \%) \\
\text { Part-worth }\end{array}$ & $\begin{array}{c}\text { Segment V } \\
(17.7 \%) \\
\text { Part-worth }\end{array}$ & $\begin{array}{c}\text { Segment VI } \\
(7.6 \%) \\
\text { Part-worth }\end{array}$ & $\begin{array}{c}\text { Overall } \\
(100 \%) \\
\text { Part-worth }\end{array}$ \\
\hline \multicolumn{8}{|l|}{ Color: } \\
\hline Green & $-0.15^{*}$ & $0.50^{* \mathrm{z}}$ & $1.27^{* \mathrm{z}}$ & $2.01^{* z}$ & $0.90^{\mathrm{z}}$ & $-0.83^{* \mathrm{z}}$ & $0.91^{z}$ \\
\hline Brown & $-0.29^{* z}$ & $-0.93^{\mathrm{z}}$ & $-1.54^{* z}$ & $-1.30^{* z}$ & $-0.55^{* \mathrm{z}}$ & $0.67^{* z}$ & $-0.85^{z}$ \\
\hline Red & $-0.12^{*}$ & $0.17^{* z}$ & 0.01 & $-0.22^{* z}$ & $0.25^{* \mathrm{z}}$ & $0.23^{* z}$ & 0.03 \\
\hline Yellow & $0.37^{* z}$ & $0.08^{* z}$ & -0.07 & $-0.30^{* z}$ & $-0.30^{*} \mathrm{z}$ & 0.15 & $-0.08^{z}$ \\
\hline Orange & $0.19^{* z}$ & $0.19^{* \mathrm{z}}$ & $0.34^{* z}$ & $-0.18^{*_{z}}$ & $-0.29^{*_{\mathrm{z}}}$ & $-0.22^{* \mathrm{z}}$ & -0.01 \\
\hline Relative importance $(\%)$ & $29.5^{*}$ & $59.8^{*}$ & $69.6^{*}$ & $93.2^{*}$ & $45.0^{*}$ & $52.8^{*}$ & $74.6^{\mathrm{z}}$ \\
\hline \multicolumn{8}{|l|}{ Price/kg: } \\
\hline Vector & $-0.25^{\mathrm{z}}$ & $-0.26^{* z}$ & $0.02^{*}$ & $-0.06^{* z}$ & $-0.27^{z}$ & $-0.34^{* z}$ & $-0.18^{z}$ \\
\hline$\$ 0.69$ & -0.17 & -0.18 & 0.01 & -0.04 & -0.19 & -0.23 & -0.12 \\
\hline$\$ 1.69$ & -0.42 & -0.44 & 0.03 & -0.10 & -0.46 & -0.57 & -0.30 \\
\hline$\$ 2.69$ & -0.67 & -0.70 & 0.05 & -0.16 & -0.73 & -0.91 & -0.48 \\
\hline$\$ 3.69$ & -0.92 & -0.96 & 0.07 & -0.22 & -1.00 & -1.25 & -0.66 \\
\hline Relative importance (\%) & $33.9^{*}$ & $33.1^{*}$ & $1.2^{*}$ & $5.4^{*}$ & 25.2 & $35.6^{*}$ & $22.9^{z}$ \\
\hline \multicolumn{8}{|l|}{ Vitamin $C$ (content) } \\
\hline $75 \%$ & $-0.42^{* \mathrm{z}}$ & $0.09^{* z}$ & $-0.54^{* z}$ & $-0.03^{*}$ & $0.52^{* \mathrm{z}}$ & $0.15^{{ }^{z} \mathrm{z}}$ & 0.01 \\
\hline $100 \%$ & 0.03 & $-0.08^{z}$ & -0.10 & 0.02 & -0.07 & 0.04 & -0.03 \\
\hline $125 \%$ & $0.40^{* z}$ & -0.01 & $0.64^{* z}$ & 0.01 & $-0.44^{* z}$ & $-0.18^{* z}$ & 0.03 \\
\hline Relative importance (\%) & $36.6^{*}$ & $7.1^{*}$ & $29.2^{*}$ & $1.4 \%$ & $29.8^{*}$ & $11.6^{*}$ & $2.5^{z}$ \\
\hline Adjusted $R^{2}$ & 0.34 & 0.44 & 0.43 & 0.68 & 0.43 & 0.44 & 0.49 \\
\hline
\end{tabular}

Table 1. Part-worths, relative importance, and adjusted $R^{2}$ for the six clusters based on preferences for bell pepper attributes.

${ }^{\mathrm{z}}$ Significant at the 0.10 level when compared to zero in a two-tail $t$ test.

*Significant at the 0.10 level when compared to overall sample in a two-tail $t$ test. 
highest part-worth after green and brown, respectively.

The relative importance of retail price in the overall sample $(22.9 \%)$ was not representative of Segments III or IV, which expressed relative importance values of only $1.2 \%$ and $5.4 \%$, respectively. These results, together with the small coefficients for "Vector" in Table 1, indicate that neither segment was sensitive to price. The corresponding part-worths for each of the four test prices shown in Table 1 are simply the product of the Vector coefficient and the price. For all segments except III, partworths decreased as retail price increased. This is consistent with the general observation that consumers prefer lower prices. The small positive relationship between price and partworth in Segment III is not significantly different from zero.

With a value of only $2.5 \%$, the relative importance of vitamin C content to the overall panel seemed to indicate that respondents were completely indifferent to this attribute. However, these aggregate results masked the complexity of preferences with respect to vitamin $\mathrm{C}$ content. The cluster analysis revealed that three segments (I, III, and V), comprising 40\% of the sample, ranked vitamin $\mathrm{C}$ content as the first or second most important attribute, and that Segments I and III preferred the highest level of vitamin C, while Segment V preferred the lowest. Only Segments II and IV indicated no marked preference for this attribute.

Note that most retail stores do not display the vitamin C content of bell peppers as prominently as their price. Thus, in our study consumers were compelled to consider their preferences for this attribute more deliberately than they might in a normal shopping situation. Also, the vitamin $\mathrm{C}$ content provided in nutritional information is usually based on a certain serving size of the raw product (e.g., $130 \%$ of RDA for a medium-size pepper of $148 \mathrm{~g}$ ). Since many preparations use bell peppers steamed, sauteed, or stir-fried, some of the vitamin $\mathrm{C}$ may be lost in cooking. In that case, nutritional information would have to be adjusted for consumers who keep track of their daily nutrient intake.

Demographic and behavioral variables. Segments of the sample were identified on the basis of their part-worths for color, retail price, and vitamin $\mathrm{C}$ content. This section presents the demographic and behavioral characteristics of the consumers belonging to those different segments.

Few of the segments showed significant differences from the overall sample based on the five demographic variables of age, gender, education, family size, and income (Table 2 ). Respondents in Segment I had significantly less education than the group as a whole, while Segment IV was composed of a significantly higher percentage of females than the overall sample. The segment that was most differentiated from the overall sample on demographic criteria was Segment VI, which was composed of significantly older consumers with smaller family size and lower income than the overall sample. Segments II, III, and V were not significantly different from the overall sample on any of the demographic dimensions.

Behavioral variables were determined from the 12 questions on the survey that related to past purchases and usage (cooked or raw). The behavior of consumers in Segments I, II, and IV was significantly different from those in the overall sample in their prior purchases of white (I, II, IV), purple (II), and yellow (IV) bell peppers (Table 2). Consumers in Segment III were significantly more likely to use bell peppers in cooking, while consumers in Segment IV used fewer raw peppers in salads than did the overall sample. Segment V had a significantly higher percentage of consumers who had purchased bell peppers of any kind in the last month.

The hypothesis tests in Table 2 determined whether the value of each demographic or behavioral variable for each segment differed significantly from that of the overall sample. Another way of comparing the impact of these variables is to use a multinomial logit model to determine how much a one-unit change in the overall sample mean for a given variable would change the probability of membership in each segment, and whether that change is significantly different from zero (Table 3 ).

The sign, magnitude, and statistical significance of the coefficients from the multinomial logit model provide a measure of the impact that the demographic and behavioral variables have in determining the structure of segment membership. As an example of the effect of the continuous variables, the education coefficient of -0.0098 for Segment I indicates that an increase of 1 year in the average number of years of education for the overall sample would decrease the probability of membership in Segment I by $0.98 \%$. Similarly, an increase in the overall average household size by one person would increase the probability of membership in Segment III by $1.86 \%$. Attention must also be paid to the statistical tests: an increase of $1 \%$ in the proportion of consumers who bought orange peppers in the last 4 weeks would appear to increase the probability of membership in Segment IV by $66.8 \%$, except that the coefficient is not significantly different from zero because of the large standard error that presumably resulted from the scarcity of respondents who had bought orange peppers.

In general, among the demographic variables only gender and household size were consistently significant in determining segment membership, while many more of the behavioral variables had significant impact. For example, a $1 \%$ increase in the overall percentage of consumers who had purchased any color of bell pepper in the last 4 weeks would increase the probability of membership in Segment V by $13.08 \%$. Recalling that an increase in one segment must be offset by decreases elsewhere (such that the row coefficients sum to zero), the increase in Segment $\mathrm{V}$ would primarily come from the $11.86 \%$ decrease in the probability of membership in Segment IV.

Applications to marketing strategies. The

Table 2. Demographic and behavioral variables describing the six-cluster solution based on preferences for bell pepper attributes.

\begin{tabular}{|c|c|c|c|c|c|c|c|c|}
\hline Variable & $\mathrm{N}$ : & $\begin{array}{c}\text { Segment I } \\
45\end{array}$ & $\begin{array}{c}\text { Segment II } \\
108\end{array}$ & $\begin{array}{c}\text { Segment III } \\
52\end{array}$ & $\begin{array}{c}\text { Segment IV } \\
120\end{array}$ & $\begin{array}{c}\text { Segment V } \\
77\end{array}$ & $\begin{array}{c}\text { Segment VI } \\
33\end{array}$ & $\begin{array}{c}\text { Overall sample } \\
435\end{array}$ \\
\hline$\%$ of Sample & & $10 \%$ & $25 \%$ & 12.0 & $28 \%$ & $18 \%$ & $8 \%$ & $100 \%$ \\
\hline Age (years) & & 38.31 & 39.89 & 38.00 & 37.68 & 40.32 & $45.66^{*}$ & 39.40 \\
\hline Gender ( $\%$ female $)$ & & 70 & 70 & 80 & $83^{*}$ & 74 & 72 & 76 \\
\hline Education (yrs) & & $13.71^{*}$ & 14.78 & 14.68 & 14.43 & 14.71 & 15.10 & 14.56 \\
\hline Family size (persons) & & 2.93 & 2.74 & 3.00 & 2.79 & 2.72 & $2.28^{*}$ & 2.78 \\
\hline Income $(10=\$ 60-\$ 65 \mathrm{~K})$ & & 6.20 & 5.76 & 5.61 & 5.89 & 5.91 & $4.21^{*}$ & 5.77 \\
\hline \multicolumn{9}{|l|}{$\begin{array}{l}\text { Purchase of bell peppers } \\
\text { in last } 4 \mathrm{wk}(\%)\end{array}$} \\
\hline Any color & & 62.2 & 71.2 & 75.0 & 65.0 & $80.5^{*}$ & 62.5 & 70.0 \\
\hline Green & & 67.4 & 75.2 & 78.8 & 74.2 & 79.2 & 71.9 & 75.0 \\
\hline Yellow & & 23.9 & 28.6 & 19.2 & $13.3^{*}$ & 26.0 & 18.8 & 21.5 \\
\hline White & & $2.17^{*}$ & $13.3^{*}$ & 7.7 & $4.2^{*}$ & 5.2 & 12.5 & 7.4 \\
\hline Purple & & 0.0 & $7.6^{*}$ & 0.0 & 0.0 & 1.3 & 3.1 & 2.3 \\
\hline Red & & 19.6 & 9.5 & 9.6 & 8.3 & 6.5 & 9.4 & 9.7 \\
\hline Orange & & 0.0 & 1.9 & 0.0 & 0.8 & 1.3 & 0.0 & 0.9 \\
\hline Black & & 0.0 & 0.0 & 0.0 & 0.0 & 1.3 & 0.0 & 0.2 \\
\hline Brown & & 0.0 & 0.0 & 0.0 & 0.0 & 0.0 & 0.0 & 0.0 \\
\hline Total purchased last 4 wks (kg) & & 0.88 & 1.29 & 1.10 & 0.91 & 1.26 & 0.89 & 1.08 \\
\hline Used in cooking $(\%)$ & & 82.9 & 85.1 & $91.5^{*}$ & 77.3 & 77.6 & 87.1 & 82.3 \\
\hline Used raw (salads) (\%) & & 68.3 & 63.4 & 53.2 & $48.2^{*}$ & 55.3 & 58.1 & 56.7 \\
\hline
\end{tabular}

${ }^{*}$ Significant at the 0.10 level (compared with the overall sample in a two-tail $t$ test.). 
Table 3. Estimated marginal probabilities for the six clusters for bell pepper attributes.

\begin{tabular}{|c|c|c|c|c|c|c|}
\hline \multirow[b]{2}{*}{ Variable } & \multicolumn{6}{|c|}{ Marginal probabilities } \\
\hline & $\operatorname{Prob}[\mathrm{Y}=\mathrm{I}]$ & $\operatorname{Prob}[\mathrm{Y}=\mathrm{II}]$ & $\operatorname{Prob}[\mathrm{Y}=\mathrm{III}]$ & $\operatorname{Prob}[\mathrm{Y}=\mathrm{IV}]$ & $\operatorname{Prob}[\mathrm{Y}=\mathrm{V}]$ & $\operatorname{Prob}[\mathrm{Y}=\mathrm{VI}]$ \\
\hline Intercept & $0.1088^{* *}$ & 0.1062 & $-0.1856^{* * * *}$ & 0.1494 & -0.0492 & -0.1297 \\
\hline Age & -0.0012 & 0.0011 & -0.0005 & -0.0022 & 0.0005 & 0.0022 \\
\hline Income & $0.0065^{*}$ & $-0.0125^{*}$ & 0.0008 & 0.0137 & 0.0027 & -0.0112 \\
\hline Gender & $-0.0589^{* * *}$ & $-0.1128^{* * * *}$ & $0.0204^{* * *}$ & $0.1761^{* * * *}$ & $-0.0166^{* *}$ & -0.0082 \\
\hline Education & $-0.0098^{* * *}$ & 0.0002 & 0.0000 & 0.0007 & 0.0038 & 0.0052 \\
\hline Household size & $0.0063^{*}$ & 0.0159 & $0.0186^{* * *}$ & $-0.0167^{* *}$ & $-0.0139^{* * * *}$ & -0.0103 \\
\hline \multicolumn{7}{|l|}{$\begin{array}{l}\text { Peppers bought } \\
\text { in last } 4 \mathrm{wk}\end{array}$} \\
\hline Any & 0.0331 & -0.0450 & $0.0604^{* *}$ & $-0.1186^{* * *}$ & $0.1308^{* *}$ & -0.0606 \\
\hline Green & $-0.0630^{* * *}$ & $-0.1292^{* * * *}$ & $-0.0211^{* *}$ & $0.2001^{* * * *}$ & 0.0003 & 0.0129 \\
\hline Yellow & $0.0238^{* * * *}$ & $0.1408^{* * *}$ & $-0.0443^{* * *}$ & $-0.1839^{* * *}$ & $0.0436^{* * *}$ & 0.0199 \\
\hline Red & $0.1014^{* * *}$ & -0.0169 & 0.0172 & $0.0842^{*}$ & $-0.1574^{* * *}$ & -0.0285 \\
\hline Orange & -0.6828 & 0.6538 & -0.8801 & 0.6683 & 0.6066 & -0.3658 \\
\hline $\mathrm{Wt}$ & $-0.0061^{* * * *}$ & 0.0042 & $0.0025^{*}$ & -0.0035 & $0.0052^{*}$ & -0.0023 \\
\hline Cooked & 0.0119 & $0.0813^{* *}$ & $0.0893^{* * *}$ & $-0.1413^{*}$ & $-0.0940^{*}$ & 0.0527 \\
\hline Raw & $0.0346^{* * *}$ & $0.1077^{* * *}$ & $-0.0357^{* * * *}$ & $-0.0607^{* * *}$ & $-0.0351^{* * *}$ & -0.0107 \\
\hline
\end{tabular}

${ }^{* * *}$ Significantly different from zero at the $0.10,0.05$, or 0.01 level, respectively.

information from Table 1 can be used to suggest possible marketing strategies for this local market based on combinations of the attributes of color, price, and vitamin $\mathrm{C}$ content. For example, Segments III and IV exhibited the strongest preference for green among all the segments, with part-worths of 1.27 and 2.01 , respectively. These two segments also were the least sensitive to price, with relative importance values of $1.2 \%$ and $5.4 \%$, respectively. Conversely, Segments I, II, V, and VI all exhibited strong preferences for non-green bell peppers and were also the most sensitive to price. This suggested that green peppers may be underpriced relative to those of other colors. Interestingly, some grocery stores may already be aware of these preference patterns and have responded to them. Certain local retailers now price green bell peppers individually, while they price others-which are displayed in a different part of the produce section-by weight. Thus, green bell peppers at some stores were recently selling at two for $\$ 1.28$ (or $\approx \$ 4.32$ per $\mathrm{kg}$, assuming a $148 \mathrm{~g}$ medium bell pepper), which is considerably higher than the $\$ 1.52$ to $\$ 2.18$ per $\mathrm{kg}$ range previously observed.

Another example involves color and vitamin C content. Segments I and III rated vitamin $\mathrm{C}$ content as relatively important and preferred more vitamin $\mathrm{C}$ to less. They also exhibited stronger preferences for yellow and orange peppers. Together these results suggest that marketing efforts designed to promote the vitamin $\mathrm{C}$ content of bell peppers would have a greater impact if associated specifically with yellow and orange peppers.

Applications to changes in segment membership. When information from Tables 1, 2, and 3 is combined, some insight may be gained into the effects that changes in the structure of segment membership can have on marketing applications. The premise is that retailers would want to increase the probability of consumers becoming members of the segments that have the greatest revenue potential.

The prospects for this exercise are limited by the requirement that good candidates for change should be segment characteristics that are simultaneously "substantial" and "acces- sible" (Kotler and Armstrong, 1996). This means that in order to implement a strategy that involves increasing membership in a segment, the potential lies with coefficients in Table 3 that are large, positive, and statistically significant (substantial), and susceptible to influence by marketing techniques (accessible). An example of a strategy that might meet all these criteria is a promotional effort to increase the proportion of females in the overall buyer population. The interpretation of the marginal probabilities in Table 3 reveals that a promotional effort resulting in a $1 \%$ increase in the overall sample mean of females to $77 \%$ (Table 2) would increase the probability of membership in Segment IV by $17.61 \%$. Table 1 reveals that Segment IV preferred green bell peppers to the exclusion of all other colors, was relatively insensitive to price, and represented slightly more than a quarter of the market share. Thus, a price increase for green bell peppers could have a greater impact on revenues if associated with promotions directed at increasing the proportion of female buyers. Whether this complex strategy would be compatible with other operative product, pricing and promotional strategies should, of course, be considered in practice.

\section{Conclusions}

The overall consumer sample used in this study viewed color as far more important in the purchase decision than retail price or vitamin $\mathrm{C}$ content. The aggregate of respondents also indicated a clear preference for green and a strong disinclination toward brown, with red, yellow, and orange intermediate between these two. For the price range used in this study, retail price was a secondary factor compared with color, while vitamin C content had a negligible effect on overall consumer preference.

If aggregate-level analysis rather than individual-level analysis had been used exclusively, the above conclusions would have exhausted the information content of the data set. Instead, cluster analysis was used to identify six distinct consumer segments in this market. The smallest of these showed a preference for brown bell peppers, indicating a limited demand for this color even though it is practically unknown in the marketplace. Two priceinsensitive segments were identified, both with strong preferences for green. Consumer perceptions toward vitamin $\mathrm{C}$ content varied widely, with some segments favoring higher levels and others favoring lower levels, while relative importance ranged from $1.4 \%$ to $36.6 \%$. Gender, household size, purchase frequency of green and yellow peppers, and use of raw peppers were the demographic and behavioral variables that determined membership in most segments.

Examples of applications suggested that: 1) differential price sensitivities could explain the practice of pricing green peppers individually while pricing those of other colors by weight; and 2) efforts to promote the high levels of vitamin $\mathrm{C}$ would be most effective if associated with yellow and orange bell peppers.

That producers who supply products with high levels of consumer satisfaction have an advantage in the market is well accepted. Conjoint analysis provides an efficient means of determining which product attributes give the highest satisfaction. Knowledge of the structure of consumer preferences can also help horticulturists develop new cultivars and devise new field practices that bring to market bell peppers with the highest degree of consumer desirability.

\section{Literature Cited}

Behe, B., R. Nelson, S. Barton, C. Hall, C.D. Safley, and S. Turner. 1999. Consumer preferences for geranium flower color, leaf variegation, and price. HortScience 34:740-742.

Bretton-Clark. 1990. Conjoint designer, version 3. Bretton-Clark, Morristown, N.J.

Bretton-Clark. 1992. Conjoint analyzer, version 3. Bretton-Clark, Morristown, N.J.

Cohen, J. and P. Cohen. 1983. Applied multiple regression, 2nd ed. Lawrence Erlbaum, Mahwah, N.J.

Gineo, W.M. 1990. A conjoint/logit analysis of nursery stock purchases. Northeastern J. Agr. Res. Econ. Apr. 1990:49-58.

Green, P.E. and K. Helsen. 1988. Conjoint internal validity under alternative profile presentations. J. Consumer Res. 15:392-397.

Green, P.E. and Y. Wind. 1973. Multi attribute decisions in marketing: A measurement approach. Dryden Press, Hinsdale, Ill.

Greene, W.H. 1995. LIMDEP, version 7.0: User's manual. Econometric Software, Plainview, N.Y.

Hardy, M.A. 1993. Regression with dummy variables. Univ. Paper Ser. on Quantitative Applications in the Social Sciences, 07-093. Univ. of California-San Diego, La Jolla.

Huang, C.L. and J. Fu. 1995. Conjoint analysis of consumer preferences and evaluations of a processed meat. J. Intl. Food and Agribusiness Mktg. 7(1):35-53.

Kotler, P. and G. Armstrong. 1996. Principles of marketing, 7th ed. Prentice Hall, Upper Saddle River, N.J.

Manalo, A.B. 1990. Assessing the importance of apple attributes: An agricultural application of conjoint analysis. Northeastern J. Agr. Resource Econ. Oct. 1990:118-124. 
Robertson, J.L. and L.H. Chatfield. 1982. Fresh flower merchandising in loose bunches. HortScience 17:593-595.

Salunkhe, D.K. 1976. Storage, processing, and nutritional quality of fruits and vegetables. CRC Press, Cleveland, Ohio.

SAS Institute Inc. 1996. SAS user's guide: Statistics, version 6.12. SAS Inst., Cary, N.C.

Shafer, B.S. and J.W. Kelly. 1986. The influence of cultivar, price, and longevity on consumer preferences for potted chrysanthemums. HortScience 21:1412-1413.
Simonne, E., R. Boozer, J. Little, J. Pitts, and M. Ruf. 1996. Colored pepper varieties respond differently to bacterial leaf spot infection, p.1114. In: Alabama. Agr. Expt. Sta. Prog. Rpt. 130.

Simonne, A.H., E.H. Simonne, R.R. Eitenmiller, H.A. Mills, and N.R. Green. 1997a. Ascorbic acid and provitamin A contents in unusually colored bell peppers (Capsicum annuum L.) J. Food Comp. Anal. 10(4):299-311.

Simonne, E., J. Kemble, and R. Boozer. 1997. Varieties for the Alabama vegetable industry and the southeast. Alabama. Agr. Expt. Sta. Bul. 632.

Townsley-Brascamp, W. and N.E. Marr. 1995. Evaluation and analysis of consumer preferences for outdoor ornamental plants. Acta Hort. 391:199-206.

U.S. Dept. of Agriculture. 1997a. Fruit and vegetable report. Natl Agr. Stat. Serv., Washington, D.C.

U.S. Dept. of Agriculture. 1997b. Market news reports-Fruit and vegetable. Natl Agr. Stat. Serv., Washington, D.C. 